\title{
Epilepsy and its effects on children and families in rural Uganda
}

\author{
*Duggan $\mathrm{MB}$
}

Spring view Cottage, More Hall Lane, Bolsterstone, S36 3ST England

\begin{abstract}
Background: This report aims to assess the impact of childhood epilepsy in an isolated rural area in Western Uganda, with little access to medical care, via its effect on children and families. Basic information on 440 affected children, clinically examined at 19 rural centres, was collated and data on seizure pattern and duration analysed, together with information on school attendance of older children.

Objective: To publicise the consequences of undertreated illness, and to encourage improved management of this condition. Results: Distribution by seizure type was: generalised 61\%, focal 33\%, and miscellaneous 6\%. When information on all seizure types was combined, a 'typical seizure' lasted $<1$ hour, followed by coma. The typical age of onset and duration of illness approximated $2 \frac{1}{2}$ and 4 years respectively. Modal frequency and duration of seizures suggested that $\sim 96$ hours might be 'lost' to seizures over 4 years. Twenty four children had delayed global or motor development; a further 93 were reported to have 'poor understanding'. Information on school attendance available on 162 of 231 school aged children indicated that 92 were attending and 70 not attending school. Fifty eight percent of children $>10$ yrs old attending school and $68 \%$ of non-attendees, had never progressed beyond the entry class.

Conclusion: The unexpected prevalence of apparent cognitive delay is discussed, together with strategies for prevention and management of epilepsy at community level.

Key words: Antiepileptic drugs, prolonged coma, cognition, traditional treatment, schooling

African Health Sciences 2013; 13(3): 613 - 623 http:/ /dx.doi.org/10.4314/ahs.v13i3.14
\end{abstract}

\section{Introduction}

The marked shortfall in care for people with epilepsy, which is common in poorly resourced regions, may be summarised as lack of access to sustainable antiepileptic treatment exacerbated by lack of community awareness. Failure, attributable to inadequate maternal and child health care, to prevent some forms of secondary epilepsy, is also acknowledged. There is surprisingly little information about the wider family and social consequences of (untreated) childhood epilepsy.

This report assesses the burden of childhood epilepsy in a rural Ugandan community, focussing on the impact of the disease on the lives of affected children and their families. Rukungiri district in western Uganda is a remote volcanic area with seasonal malaria. At the time of the study the population of approximately 194,000 was served

\begin{tabular}{|l|}
\hline *Corresponding author: \\
Dr. Maureen B Duggan \\
Springview Cottage, More Hall Lane \\
Bolsterstone, S36 3ST England \\
Previously: Department of Paediatrics \\
Mbarara University of Science and Technology \\
P. O. Box 1410 \\
Mbarara Uganda \\
Email: maureen.duggan1@btinternet.com \\
\hline
\end{tabular}

African Health Sciences Vol 13 Issue 3 September 2013 by one government and two mission hospitals (no paediatrician $)^{1}$.

The information here reported was obtained in the course of a time-limited survey of children with long standing seizures, attending for assessment prior to integration of antiepileptic drug treatment AED into an ongoing community initiative ${ }^{1}$, supported by the Christian Blind Mission. A survey of children with seizures, was carried out by the author assisted by a Rukiga speaking field worker / interpreter ${ }^{1}$. Broadening of the original survey objectives, which had been to quantify the local need for, and plan provision of appropriate antiepileptic drugs AED, is described in the methods section. It was not feasible to recruit other staff, or to change the time frame or methodology to meet the extended objectives. The final objective of this secondary arm of the study was to assess the burden of childhood epilepsy in terms of gross neurological deficit, learning difficulty as perceived by parents, plus disruption of family life due to (untreated) seizures. The local Medical Officer of Health was informed of the study, which was operational in nature. 


\section{Method}

Children presenting with recurrent seizures (see above) were assessed during a multidisciplinary survey of disabled children in Rukungiri district of Western Uganda (population $<15$ years $\sim 195,000$; Uganda 1991 census $^{2}$ ). Two teams (one consisting of a paediatrician, and the other an orthopaedic surgeon and physiotherapist, both supported by a nurse manager/ team leader [P Gilmer] and two interpreters), held assessment clinics at 19 sites in small towns throughout Rukungiri district during the month of August 1997. This report considers only children for whom epilepsy was the sole or major complaint, since those also disabled by mobility problems were assessed by the surgical rehabilitation team. As already stated, the original objective of the paediatric survey had been to quantify the local burden of childhood epilepsy, and advice on suitable AED. However, as the work progressed, it became apparent that a broader approach than simple assessment of need for AED was indicated, and the methodology and objectives were modified accordingly. Two important issues had emerged. Firstly, a number of parents expressed concerns about the child's 'difficulty in understanding', which had, in some cases, led to withdrawal from school. The methodology was, therefore, extended to include more structured recording of information on school attendance, and perceived intellectual deterioration. Furthermore, it became clear that the then traditional view that short generalised seizures in febrile children between 6 and 60 months were benign, did not fit the facts. Consequently, children (reported as febrile during seizures) were no longer excluded. The late and 'dynamic' adaptation of the method explains some disparity of numbers, while distance from children's homes and schools limited access to information.

Prior to each visit to a town, the time and purpose of the assessments had been publicised and explained by local community and religious leaders. Before each (paediatric) session, children and carers were given a short talk on management of seizures, at which common misunderstandings especially those resulting in stigma were discussed. Fear of contagion, a common concern expressed during these general sessions, was not included in individual assessments, but is touched upon in the discussion. The method of history taking and examination is described elsewhere ${ }^{1}$. In summary, each individual assessment, carried out by a sole investigator supported by a Rukiga speaking interpreter, consisted of a (vernacular) history in order to establish seizure type, followed by a clinical examination focussing on neurological status and development. No specific tests of hearing, visual acuity, or intellectual ability were performed. Nor was any formal cognitive or educational assessment feasible. Neither were there any facilities for EEG or other investigations e.g. for genetic confirmation of syndromes such as Down's.

Notwithstanding newer insights into the condition following neuro-physiological advances, the criteria used for a clinical diagnosis of epilepsy were a clear description of recurrent and paroxysmal time-limited changes in motor activity or behaviour ${ }^{3}$. The exclusion, early in the study, of children in the $6 \mathrm{~m}$ to $<5$ years age band, suffering from short $(<15$ minutes) generalised seizures of tonic-clonic type associated with fever, had resulted in exclusion of $178 / 342(52 \%)$ of all children $<5$ y. Children were initially classified by seizure type using the International Classification ${ }^{4,5}$. This was updated to comply with the revised terminology published by the International League against Epilepsy ILAE 2010 ${ }^{6,7}$ supported by Panayiotopoulos ${ }^{8}$, and is therefore different from that in our previous report ${ }^{1}$.

Based on clinical assessment, 440 of 618 children presenting with recurrent seizures, were diagnosed with epilepsy: the 178 excluded children will be discussed later. The burden borne by the children and their families is considered in the context of rural Uganda. The effect on quality of life is assessed in terms of the disruption caused by long and /or frequent seizures, and of reported deterioration in intellect,(mobility), and school attendance. The limitations in history, lack of technical support for diagnosis, and inability to carry out further sensory and educational assessment, will be discussed. Statistical analysis was not undertaken when precision of time estimates was in doubt.

\section{Results}

The sex and age distribution among the 440 children was as follows:- 259 boys and 181 girls fulfilled the diagnostic criteria (M:F ratio 1:0.7), their ages ranging from 4 months to 18 years (age was unknown in 10 pre-pubertal children ). The majority $(71 \%$ boys and $64 \%$ girls) were younger than 10 years old. The distribution of different seizure types is illustrated in table 1, using the updated International Classification of Epilepsy ${ }^{6,7}$. 
Table 1: Distribution of different seizure types among 440 rural Ugandan children with epilepsy

\begin{tabular}{|c|c|c|}
\hline General seizures & $\begin{array}{l}\text { Number in } \\
\text { each group }\end{array}$ & $\begin{array}{l}\text { during seizures had been reported in } 31 \text { children (19 } \\
\text { with tonic-clonic GS and } 11 \text { with FS (with loss of }\end{array}$ \\
\hline Generalised tonic-clonic seizures & 235 & consciousness). The data on these 31 children were \\
\hline Generalised tonic seizures & 32 & similar in many respects to those of the 178 excluded \\
\hline Akinetic , absence and myoclonic seizures & 23 & with 'benign febrile seizures' ${ }^{1}$. \\
\hline Total generalised seizures & 290 & \\
\hline Partial seizures & & Estimating the severity of seizures and overall \\
\hline Simple partial Seizures & 27 & impact of epilepsy \\
\hline Complex partial seizures & 101 & The severity of episodes was estimated by the average \\
\hline Temporal lobe seizures & 12 & length of a typical seizure and any post-seizure coma, \\
\hline $\begin{array}{l}\text { Partial to general, breath holding attacks and } \\
\text { unclassified }\end{array}$ & 10 & $\begin{array}{l}\text { while the impact of the disease was estimated by } \\
\text { the age of onset of seizures, the duration of the }\end{array}$ \\
\hline Total partial seizures & 150 & illness, the frequency of seizures, and also by the \\
\hline Grand total seizures & 440 & occurrence of associated conditions such as cerebral \\
\hline \multicolumn{2}{|c|}{$\begin{array}{l}\text { Nearly two thirds } 290(65.9 \%) \text { of children had } \\
\text { suffered from generalised seizures (GS) and } 150 \\
(34 \%) \text { from focal seizures (FS). The most common } \\
\text { seizure type }(235 ; 53 \%) \text { was GS (tonic-clonic type) } \\
\text { followed by FS with loss of consciousness (101; } \\
23 \%) \text { :the overall seizure pattern is described in detail } \\
\text { elsewhere }{ }^{1} \text {,using the older classification. Fever }\end{array}$} & $\begin{array}{l}\text { palsy or apparent intellectual deterioration. } \\
\text { Information on timing, frequency and duration of } \\
\text { seizures was largely dependent on parental recall } \\
\text { without benefit of clocks or calendars. The distinction } \\
\text { between seizures and post-seizure coma was not } \\
\text { always clear, so that much information was unsuitable } \\
\text { for statistical analysis. Very few children (13) had } \\
\text { received treatment with AED (and virtually none } \\
\text { had persisted in treatment. }\end{array}$ \\
\hline
\end{tabular}

Table 2: Severity of the epileptic condition in 411 Ugandan children with full information, as evidenced by mean duration of seizures and of post seizure coma, and by mean age of onset and of duration of the condition.

\begin{tabular}{llllcl}
\hline Type of Seizure & $\begin{array}{c}\text { Subjects } \\
\text { with full } \\
\text { information }\end{array}$ & $\begin{array}{l}\text { Mean age } \\
\text { of onset }\end{array}$ & $\begin{array}{l}\text { Mean duration } \\
\text { of illness prior } \\
\text { to assessment }\end{array}$ & $\begin{array}{c}\text { Mean duration Approximate } \\
\text { of seizure }\end{array}$ & $\begin{array}{l}\text { mination post- } \\
\text { durate } \\
\text { seizure coma }\end{array}$ \\
\cline { 2 - 6 } & number & years & Years & minutes \\
\hline Absence seizure & 3 & 2.3 & 5 & 24 & no values \\
Myoclonic seizure & 1 & 0.5 & no values & no values & 0 \\
Tonic-clonic general & 227 & 2.8 & 4.3 & 41 & 80 \\
seizure & & & & & \\
Tonic generalised seizure & 28 & 3.0 & 4.0 & 41 & 80 \\
Akinetic seizure & 13 & 4.5 & 4.6 & 2.5 & 75 \\
Simple partial seizure & 25 & 2.4 & 2.2 & 36 & $62^{*}$ \\
Complex partial seizure & 93 & 2.2 & 4.6 & 49 & $105^{* *}$ \\
Partial to general seizure & 6 & 1.0 & 2.9 & 105 & $280^{* * *}$ \\
Temporal lobe s. & 12 & 3.7 & 5 & 39 & 0 \\
Breath-holding attack & 2 & 0.6 & 3.5 & 5 & 0 \\
Unclassifiable s. & 1 & 4 & 2 & no values & 0 \\
\hline
\end{tabular}

Information simplified since numbers not identical for all listed parameters. Duration of GTC seizures and of post-ictal coma calculated with following exclusions:- 3 children with seizures $>24$ h duration, 53 children who woke immediately, and 6 children with post-seizure coma lasting $>24 \mathrm{~h}$ respectively. Two children with otherwise typical SPS, and 2 with temporal lobe seizures, reported post seizure drowsiness.

Exclusions: - *12 without coma, ** 4 without coma and 9 with no information, *** 3 with no information, and $* * * * 2$ with post-ictal drowsiness. 
Table 2 summarises information on the severity of the illness with respect to the above mentioned features viz :- the average age of onset of seizures, the duration of illness prior to this assessment, and the length of a typical seizure and post seizure coma if present. In view of the uncertainty of the time estimates, this information is given for comparison only. A more useful estimate of the time burden of seizures and post-seizure coma is given by expressing the data in a frequency distribution (table 3), and comparing GS and FS (post-seizure coma was reported to follow some FS) but excluding atonic and absence GS.

It is evident that in at least $99(36 \%)$ of 274 children (column 1 table 3) children with GS, and
$52 / 148(35 \%)$ of children with all types of FS, a 'typical' seizure lasted longer than an hour. Similarly, typical post seizure coma lasted $>1$ hour in at least $106 / 274(39 \%)$ children with general and 63/148 $(42 \%)$ children with focal seizures ( with loss of consciousness). No descriptive information on seizures or post seizure coma was available for 19 and 62 children respectively (table 3). No attempt was made to distinguish nocturnal from daytime seizures, and no analyses were undertaken. The frequency of seizures as recalled by carers (table 4) indicates that the modal frequency was monthly, which applied to $128(29 \%)$ of children, while 31 $(7 \%)$ children suffered from daily seizures.

Table 3: Distribution of duration of typical seizures and of post seizure coma; times estimated by carers. Comparing general and partial seizures, and excluding absence, akinetic seizures, from general seizures because of difficulty in evaluation.

\begin{tabular}{|c|c|c|c|c|}
\hline \multirow[t]{3}{*}{ Time periods in hours } & \multicolumn{2}{|c|}{ Duration of typical seizure } & \multicolumn{2}{|c|}{ Duration of typical post- seizure coma } \\
\hline & General seizures & Partial seizures & General seizures & Partial seizures \\
\hline & number & number & number & number \\
\hline$\overline{\text { zero }}$ & & & 66 & 36 \\
\hline$<0.25$ & 95 & 50 & 20 & 8 \\
\hline 0.25 to $<0.5$ & 24 & 7 & 15 & 8 \\
\hline 0.5 to $<1.0$ & 45 & 31 & 27 & 11 \\
\hline 1 to $<2$ & 70 & 31 & 55 & 32 \\
\hline 2 to $<3$ & 20 & 6 & 27 & 8 \\
\hline 3 to $<6$ & 8 & 12 & 11 & 13 \\
\hline 6 to $<12$ & 0 & 0 & 6 & 7 \\
\hline$>1$ day & 1 & 3 & 7 & 3 \\
\hline unknown & 11 & 8 & 40 & 22 \\
\hline Total number in group & 274 & 148 & 274 & 148 \\
\hline
\end{tabular}

Table 4: Range and distribution of frequency of all types of seizure in 440 Ugandan children; as estimated by carers

\begin{tabular}{lc}
\hline $\begin{array}{l}\text { Descending order of frequency } \\
\text { of seizures per stated period }\end{array}$ & $\begin{array}{c}\text { No of } \\
\text { subjects per } \\
\text { group }\end{array}$ \\
\hline >1 per day & 8 \\
1 per day & 23 \\
3 to 5 per week & 9 \\
2 per week & 8 \\
1 per week & 38 \\
2 to 3 per month & 53 \\
1 per month & 128 \\
6 per year & 40 \\
3 to 4 per year & 43 \\
2 per year & 39 \\
1 per year & 23 \\
unpredictable frequency & 13 \\
No record & 15 \\
\hline
\end{tabular}


Based on the data in tables 3 and 4, we inferred that a 'typical' child with moderately severe epilepsy, and suffering monthly seizures followed by coma (approximating 2 hours loss of consciousness) might 'lose' around 24 hours annually and 96 in a typical 4 year illness.

The sequelae of epilepsy may be defined as direct i.e. concerned with neurological development, or indirect, as when injury occurs during a seizure. Less definite reported effects included exclusion from school of children with frequent seizures or prolonged coma, or withdrawal from school because of perceived 'learning difficulty' (see below). Table 5 illustrates the prevalence of a number of associated complications, and includes three children with 'syndromes', Down's, Seckel's and possible San Filippo syndrome respectively, all diagnosed clinically ( supported by reference ${ }^{9}$ when possible). Two other children had odd facial features, with unilateral microphthalmia and (familial) very small ears respectively, neither identified as a syndrome? Extensive scarring was noted in eight children, reported to follow burns or falls during seizures, and one child had a corneal scar possibly related to exposure keratitis (no measles association). Thirty two children had signs of evolving (7) or established (25) cerebral palsy, most commonly hemi-plegia ${ }^{1}$. Twenty four had clinical signs of marked delay in gross motor or global development (15 and 9 respectively).

Table 5: Exacerbating conditions associated with Epilepsy in 440 Ugandan children
Carers of $93(21 \%)$ volunteered that children had 'difficulty in understanding': in 11 this was thought to have begun after a severe fit, and the perceived 'difficulty' often appeared to have a definite, even if gradual, onset. Features of 'difficulty in learning or understanding' as described by carers included inability to understand instructions or to function independently (18 had been withdrawn or excluded from school). 'Understanding' was reported to have deteriorated gradually in a further 11 . None of these 104 (representing 24\% of all) children had clinical evidence of neurological deficit. The prevalence of seizure types was similar in children with learning difficulties to that of all children (see above) viz:- 48 (51\%), $22(23 \%) 3(3 \%)$ of seizures being respectively generalised (tonic-clonic in type), focal with loss of consciousness, or focal with psychic phenomena ( c.f. table 1) . Parents of a number of these children remarked on their aggressive behaviour (e.g. beating school mates), or incapacity e.g. one child often forgot his trousers, one was no longer able to dress himself or go to the latrine alone, while another was now unable to 'do work'.

\begin{tabular}{lc}
\hline Associated syndromes & 3 \\
Neuro-developmental complications \\
Deafness & 7 \\
Visual impairment & 3 \\
Nystagmus & 2 \\
Cerebral palsy & 28 \\
Cerebral palsy evolving or & 7 \\
uncertain signs & \\
Global developmental delay & 8 \\
Gross motor development delay & 15 \\
Learning difficulty & 67 \\
Behavioural disturbance & 12 \\
Indirect Complications & \\
Burn scars (burnt during seizure) & 5 \\
Scars (injury during a seizure) & 3 \\
Signs of malnutrition & 7 \\
Keratomalacia & 1 \\
\hline
\end{tabular}


Carers of $93(21 \%)$ volunteered that children had 'difficulty in understanding': in 11 this was thought to have begun after a severe fit, and the perceived 'difficulty' often appeared to have a definite, even if gradual, onset. Features of 'difficulty in learning or understanding' as described by carers included inability to understand instructions or to function independently (18 had been withdrawn or excluded from school). 'Understanding' was reported to have deteriorated gradually in a further 11 . None of these 104 (representing 24\% of all) children had clinical evidence of neurological deficit. The prevalence of seizure types was similar in children with learning difficulties to that of all children (see above) viz:- 48 (51\%), $22(23 \%) 3(3 \%)$ of seizures being respectively generalised (tonic-clonic in type), focal with loss of consciousness, or focal with psychic phenomena ( c.f. table 1). Parents of a number of these children remarked on their aggressive behaviour (e.g. beating school mates), or incapacity e.g. one child often forgot his trousers, one was no longer able to dress himself or go to the latrine alone, while another was now unable to 'do work'.

\section{School attendance}

Of the 231 children aged between 5 and $<15$ years, school attendance habits had been recorded on 162 (70\%, table 6). Ninety two of these were definitely attending school and 70 were definitely not. A significantly higher proportion of girls were at school compared with boys [47/71 (66\%) and 45/91 (49\% )respectively ; chi $^{2}=17.8$ with Yates correction] . The proportion of all children attending school was significantly lower in older children ( percentage attendance in age groups 5 to $<10$ to and 10 to $<15$ yrs being $60 \%$ and $52 \%$ respectively, chi $^{2}=22$ with Yates' correction). The decrement in school attendance with increasing age was more marked in girls; percentage attendance in the two age bands being $66 \%$ and $56 \%$ for girls ( $\mathrm{chi}^{2}=19.5$ with Yates correction ) and $51 \%$ and $42 \%$ for boys ( NS). Twenty one $21 / 36(58 \%)$ of children $>10$ years were still in the entry class (Primary 1) and 14 of the 21 children withdrawn from school had never progressed beyond P1 (table 6). There appeared to be no obvious link between seizure frequency and school attendance. The possible significance of these findings in a poor rural area is discussed. Proportion of girls were at school compared with boys $[47 / 71$ $(66 \%)$ and $45 / 91(49 \%)$ respectively $;$ chi $^{2}=17.8$

Table 6 : Schooling behaviour and progress of 231 Ugandan children aged 5 to $<15 y$ rs with epilepsy

\begin{tabular}{lcllccc}
\hline Age Group & All subjects & $\begin{array}{l}\text { No information } \\
\text { on schooling }\end{array}$ & $\begin{array}{l}\text { Known school Not } \\
\text { ing behaviour } \\
\text { at } \\
\text { achool }\end{array}$ & At school & $\begin{array}{c}\text { Inentry } \\
\text { class 'P1 }\end{array}$ \\
\hline 5 to $<10$ yrs & 136 & 43 & 93 & 37 & 56 & 50 \\
10 to $<15$ yrs & 95 & 26 & 69 & 33 & 36 & 21 \\
5 to $<15$ yrs & 231 & 69 & 162 & 70 & 92 & 71 \\
\hline
\end{tabular}

Further information on 70 children not now attending school ( column 5 above)

\begin{tabular}{lclllc} 
Age group & Never at & $\begin{array}{l}\text { No information } \\
\text { on schooling }\end{array}$ & \multicolumn{3}{l}{$\begin{array}{l}\text { Highest Primary school class achieved before } \\
\text { withdrawal or exclusion from school }\end{array}$} \\
\cline { 4 - 6 } & & 13 & $\mathbf{P 1}$ & $\mathbf{P 2}$ & Higher than P2 \\
\hline 5 to $<10$ yrs & 18 & 13 & 8 & 5 & 0 \\
10 to 15 yrs & 5 & 26 & 14 & 5 & 2 \\
5 to $<15$ yrs & 23 & 26 & & 2 \\
\hline
\end{tabular}

\section{Anthropometry}

The nutritional status of the 395 children $<15$ yrs of age was assessed by anthropometry when equipment was available. Specifically:- weight, height and head circumference were measured on 174, 258, and 300 children respectively. Inspection of (mean (SD)) weight and height for age data indicated reasonable linear and weight growth, and due to age uncertainty, no statistical comparisons were done. Girls $<10$ yrs old $(\mathrm{n}=39)$ appeared marginally better nourished than the 69 boys :-Mean (SD) WHZ was 0.3(1.42) and $0.79(1.05)$ respectively $\mathrm{t}=1.99 \mathrm{p} \sim 0.05$ (unpaired data, and WHO $2007^{10}$ reference data).Ten children were grossly microcephalic ( 3 girls and 7 boys ) using a negative deviation of $-3.0 \mathrm{SD}$ as a cut-off point for a diagnosis of severe microcephaly ( reference data being neither continuous by age nor 
globally validated. The diagnosis was clinically obvious in 6 . There was no significant sex difference in age-adjusted head circumference, between 178 boys and 122 girls :- Mean (SD) 0.16 ( 1.409) and 0.03 (1.573) respectively, $\mathrm{t}=0.82$, Student's $\mathrm{t}$ test for unpaired data, and reference data due to Needlman ${ }^{11}$ and Shann et al ${ }^{12}$.

\section{Traditional beliefs and health seeking practices}

No structured attempt was made to quantify information on cultural beliefs or health seeking behaviour with respect to epilepsy, though superstitions and stigma had been discussed with attending carers before each clinic, and will be mentioned later. Some information volunteered by parents was recorded. For example an association between the time of seizures and phases of the moon was often volunteered; the 'link' being recorded in 18 cases (probable under-recording). Use of traditional medicine was so commonly mentioned that specific enquiries were later addressed to $79(18 \%)$ parents. Sixty two of these $(78.5 \%)$ had used traditional medicine, nearly half (30) reporting it to be effective. Only thirteen had used pharmacological AED; phenobarbitone in eleven and carbamazapine (prescribed in a mission hospital) in two. Four reported changing from traditional to 'western' treatment, neither being effective in two.

\section{Etiology of epilepsy}

Absence of the now commonplace facilities for further investigation e.g. genetic radiological, metabolic and electrophysiological, left us totally reliant on history and clinical examination, supported by simple reference ${ }^{9}$. Investigation for a possible genetic cause would have been indicated in the 41 children who had presented either with a similarly affected sibling, or a clinically diagnosed (genetic) dysmorphia'. The history was sometimes suggestive of secondary epilepsy viz:- as previously reported ${ }^{1}$, 35 children had signs of definite or evolving cerebral palsy (table 5), 9 of these with a history of perinatal problems or illness in infancy. A neonatal problem was recalled by mothers of 42 others (e.g. prolonged labour, small size at birth, slowness to feed, jaundice, or frank perinatal coma). The first onset of seizures followed a definite illness either during the first or second year in 29 children;- a febrile illness in 14, coma in 8 , a diagnosis of meningitis in 2 , and of measles and pneumonia one each, and reaction to immunisation in one. Thus there was evidence of secondary epilepsy in only 81/440 (18\%) of children, which is atypical of African experience ${ }^{1}$.

\section{Discussion Assessing the impact of epilepsy on child and family}

We have already stated that the scope of this study, and ability to confirm diagnoses was constrained by the lack of investigative facilities. This situation is not uncommon in rural Africa, and history, meticulous clinical examination and simple reference ${ }^{9}$ remain valued tools. Time constraints and distance from parents (who were not always present) and teachers prevented further elucidation of domestic or school related issues. Parental ( or sibling's) uncertainty about the duration and frequency of seizures precluded analysis of e.g. of an association between severity or frequency of seizures and complications such as burns, or reported effects e.g. on school attendance or intellectual deterioration.

The burden of epilepsy is particularly daunting when treatment is unavailable or ineffective. In adults it has been quantified in terms of disability adjusted life years DALYs ${ }^{13}$, but the long term implications of lost potential in children are equally important. We used as a crude measure of the overall impact, a rough approximation of the time 'lost', over the course of the illness, by a 'typical' child suffering seizures of typical duration and frequency, aware that the quality of the information was dependent on the precision of parental recall. As stated above, we estimated that a child suffering from epilepsy of 'typical severity' might lose 24 hours per year to seizures and 96 hours in a typical 4 year illness. This estimate increases dramatically when the frequency or duration is higher than average, and might, for a child suffering daily seizures, be measured in thousands of hours. We did not distinguish between day and night seizures, which may also disturb others when sleeping areas are shared. Nor should such a 'time assessment' underestimate the distress caused to a household caused by frequent short seizures: rather to emphasise the additional burden due to untreated prolonged seizures, and to hint that hypoxia may be a neglected problem. Obviously time 'lost' in seizures also affects those involved in immediate care.

The aggression or incapacity noted in some of the children with perceived learning difficulties would have required a level of supervision appropriate to a younger child. 
An increasing need for supervision is also implicit in children with deteriorating vision, hearing or difficulties in mobility due to cerebral palsy, (in 3,10, and 35 children respectively) ${ }^{1}$. Few parents complained about children's mobility, because (see above) those with major mobility problems were assessed by the rehabilitation team. The 'cost' of caring for a child with epilepsy is recognised in better resourced societies by financial allowances to carers. In this opportunistic report, it was not feasible to consider other effects on the family e.g. parental employment, income, stability of the marriage, or the child's eventual employment or marriage prospects.

\section{Progress in or withdrawal from school}

Might epilepsy have been used as an excuse for withdrawing children from school when parents could not afford to send them? Were they withdrawn because of the social consequences of the seizures or because reported 'difficulty of understanding' led to general pessimism about their futures prospects? Alternatively, might this 'difficulty in understanding' be actually due to problems with hearing, visual acuity, or dyslexia? We consider that gross deficits in hearing or vision would have been recognised by parents, or during the clinical examination, despite the fact that neither specialised sensory tests nor formal educational assessment were feasible. The forthright nature and descriptive detail of parental complaints about intellectual deterioration compelled attention, as did the fact that, despite failure to progress, so many children were still attending school.

The impact of epilepsy on education elsewhere in Africa, is often studied in children receiving AED, attending school or specialist neurological clinics, i.e. in a very different situation from these village children. Nigerian children, with treated epilepsy, attending primary school, demonstrate no gross differences from their peers ${ }^{14}$ , whereas the poor academic performance of some Nigerian adolescents with epilepsy was attributed to familial psychosocial problems or their own adverse reaction to the diagnosis ${ }^{15}$.

The possible impact of epilepsy on school attendance or performance needs to be considered in its local context, and compared with 'typical progress' in rural primary schools ${ }^{16}$. National data from Uganda ${ }^{17}$ indicate that around two thirds of children ( $65 \%$ boys and $63 \%$ girls) were enrolled in primary school in 1998, while just over a half ( $55 \%)$ reached Primary Five, and 27\% completed six years primary education. The introduction in 1997 of Universal Primary Education UPE was followed by a rapid increase in enrolment, and an increase in teacher numbers ${ }^{16,18}$. Nevertheless staff training and facilities in rural areas are still suboptimal, which may contribute to a persistently high drop-out rate from the higher classes in primary school. So too, some teachers may insist that children repeat a year, though national policy discourages this ${ }^{16}$. It is therefore difficult to interpret our data on failure to progress, school absence or fall-out among children with epilepsy. A prospective study to investigate the hypothesis that untreated epilepsy has a long term detrimental effect would be unethical as well as logistically difficult. Though we later speculate about the possible association of cognitive impairment with severe malaria, it is of interest that findings similar to these were reported from (non-malarial) Italy as recently as $1976^{19}$.

The fact that $57 \%$ of children with epilepsy (data on $70 \%$ of the 5 to $<15$ year age group) were actually attending school speaks well for the coping abilities of primary school staff, and for the efforts of parents. Nevertheless, the fact that $85(75 \%)$ of the $113(92+21)$ children who had ever been at school (table 6) had never progressed beyond P1 accords with the perceived 'difficulty in understanding' reported in $21 \%$ of all children.

\section{Perceived effect of epilepsy on cognition}

It would have been easy to dismiss the frequent unsolicited comments about 'poor understanding' because they contradict the prevailing paradigm that epilepsy is consistent with normal intelligence. But complaints, of 'poor understanding' in 93, plus frank intellectual regression in a further 11, represented $24 \%$ of all children. When questioned further, the parents described deteriorating capacity for household and related tasks, sometimes (see above) associated with outbursts of anger. The findings were not explained by the 38 children with cerebral palsy, or clinical syndromes known to be associated with intellectual impairment. Without facilities for EEG, it was impossible to identify syndromes such as GastautLennox, known to be linked with cognitive decline. In contrast to earlier studies, and despite the paucity of numerical frequency data, there was no gross association between frequent seizures (either generalised (GTCS) or focal seizures with psychic phenomena) and perceived cognitive decline ${ }^{20,21}$. 
When cognitive decline, recognised as particularly rare in childhood epilepsy, does occur, it is explained by pre-existing structural brain damage ${ }^{22}$, the adverse effect on an immature brain of early onset seizures, especially when frequent and resistant to treatment ${ }^{22,23}$ or the side effects of antiepileptic drugs $\mathrm{AED}^{24}$. These children had received virtually no AED, apart from herbal remedies, and the possible adverse affects of traditional medicine or absolute lack of treatment cannot be discounted. We also wonder whether prolonged and frequent seizures, often in poorly ventilated houses and without safe positioning of the child, might result in periods of hypoxia, with adverse sequelae.

So too, in this area of endemic seasonal malaria, it is possible that some younger children, including some of the 178 excluded with 'simple febrile seizures', might in fact, have suffered from the complex febrile seizures associated with malaria, which have a less benign prognosis ${ }^{25}$, and we urge future investigators to bear this in mind. We note that cognitive impairment has been demonstrated in Kenyan children who previously suffered severe malaria with impaired consciousness, though seizures did not feature in that report ${ }^{26}$. It must be admitted that the case for an adverse impact of epilepsy on intellect not only contradicts the prevailing paradigm, but is based on parental report, unsupported by formal intellectual assessment. The finding is not entirely without precedent ${ }^{19}$, and might fit with the recent Kenyan findings ${ }^{26}$. The nutritional status of these children, assessed by anthropometry, indicates that they were generally well cared for.

\section{Antiepileptic treatment}

The health seeking behaviour of the sub-sample $(n=79)$ questioned about their choice of treatment may not have been representative of the whole sample. Nevertheless, the small proportion (16\%) who received any AED accords with the recent estimate by $\mathrm{WHO}^{27}$ that $80 \%$ of epileptics living in developing countries do not have access to western medicine. Inhibiting factors ${ }^{27}$ include inadequacies in the health system in terms of priorities, skills, staffing and drug availability and also drug cost. At the time of this study, of three commonly used AED (phenobarbitone, phenytoin, and carbamazapine) centrally available, only the first was stocked in health centres. Consistent drug supply at district level remains a problem in many countries. Furthermore, in areas with seasonal high rainfall, sustained access to (available) medication may be prevented by impassable roads.

It has been suggested that people with epilepsy fail to seek treatment through ignorance and fear, or because they doubt its efficacy. Although $\mathrm{WHO}^{27}$ describes preference for traditional treatment as 'cultural', it is often observed that health seeking behaviour adapts when there is access to affordable and effective treatment. The high turnout for a single assessment suggests that this community was aware of the possible advantages of AED, though their current practice favoured traditional medicine. In such a remote area people may fail to cope with the exigencies of long-term compliance, even with effective treatment. It has been customary in subSaharan Africa for the responsibility for epilepsy to be borne by psychiatrists. This specialty is few in number (9 psychiatrists in Uganda in 2004) and overwhelmed by other priorities, and it is surely time for others, such as paediatricians, to share the task.

\section{The stigma of epilepsy}

Ignorance and fear of epilepsy may be particularly problematic in close and interdependent communities $^{28}$. The rural people of western Uganda traditionally fear contagion from bodily fluids (including saliva) and flatus emitted during a seizure. We were already aware that such fears were common, and felt that to discuss them at the preliminary group sessions, was part of our clinical responsibility to carers. Similar fears are causally linked with the stigmatisation of epilepsy elsewhere in Africa ${ }^{28}$, sometimes resulting in migration back to rural areas. This suggests that despite such fears and superstitions, the rural environment may be more tolerant of disability than the increasingly pressured cities.

A final measure of the societal burden due to epilepsy is its prevalence in the community. The gross attendance for assessment in Rukungiri represented $3.2 \%$ of the estimated $<15$ years population ${ }^{1}$, which, though much less than the $16.4 \%$ prevalence reported in a door to door survey in rural Tanzania, is close to reported prevalence in Gambian children ${ }^{29}$.

\section{Conclusions}

Epilepsy is common and under-treated in rural Western Uganda. The inevitable burden on families and communities includes an average of 24 hours per annum spent dealing with 'moderate' seizures. Without knowledge or access to AED, no time is 
spent 'health seeking'. It is hoped that provision of AED will reduce the burden and the sequelae of epilepsy. In their absence, these findings suggest that deteriorating intellect and capacity may also mar the progress of affected children and limit their future contribution to the community. The incomplete information on school attendance and progress, at a time of educational upheaval, is difficult to interpret. It may be time for a multi-stage prospective study to ascertain the magnitude of the problem of (childhood) epilepsy, in terms of its prevalence and social impact. If undertaken, the possible effects on epilepsy on cognitive development and psycho-social interaction should also be examined. Ethical considerations would require that all participants be offered sustained and effective AED.

With respect to general health care, prevention or expectant management of children at risk of epilepsy would be improved by incorporation, into primary health care, of follow up of neonates with peri-natal problems, and children with proven severe malaria or meningitis. Holistic care of affected children, in our context, requires greater awareness of the later vulnerability, especially of young women, when epilepsy is complicated by intellectual impairment.

It is clear that medical care for epileptic children needs to be locally accessible and at primary level. Health workers should be trained appropriately ${ }^{30,31}$ and provided with a regular supply of effective AED. Parents of children with frequent prolonged seizures should probably be provided with emergency supplies e.g. of chlorpromazine for rectal administration. Benefit will also follow general improvement in maternal and child care plus integration of epilepsy management in the IMCI (integrated management of childhood illness) ${ }^{31}$. Improved dialogue between health professionals should generate more information on the links between putative causal illness and subsequent seizures, thereby strengthening the case for prevention of both. Community based measures to prevent malaria, such as insecticide treated bed-nets ${ }^{32}$ are also relevant. For many reasons, it is time for paediatricians to play a larger part in the supervision and management of a chronic illness with such a widespread effect on children and families.

\section{Acknowledgments}

The study was carried out on a voluntary basis on behalf of Christian Blind Mission Rukungiri, to whom it has been reported. The skill of Miss $\mathrm{P}$ Gilmer who organised the survey is gratefully acknowledged.

\section{References}

1. Duggan MB. 2010 Epilepsy in rural Uganda: seizure pattern, age of onset and associated findings. African Health Sciences 2010;10:218-225.

2. Government of Uganda. Rukungiri District, The 1991 Population and Housing Census. Kampala: Uganda Government 1991 .p 8-10

3. Johnston MV. Seizures in Childhood. In: Berhrman RE, Kielgman RM and Jenson HB (eds.) Nelson Textbook of Pediatrics $17^{\text {th }}$ ed. Saunders: 2004 .p 1993 -2005

4. Commission on Classification and Terminology of the International League against Epilepsy. Proposal for Revised Clinical and Electroencephalographic Classification of Epileptic Seizures. Epilepsia 1981; 22 :489-501

5. Commission on Classification and Terminology of the International League against Epilepsy. Proposal for Revised Clinical and Electroencephalographic Classification of Epilepsies and Epileptic Syndromes. Epilepsia 1989; 30: 389-39

6. Revised terminology and concepts for organization of seizures and epilepsies: report of the ILEA Commission on Classification and Terminology 2005-2009. Epilepsia 2010 ; 52:676-685

7. Berg AT, Scheffer IE. New concepts in classification of the epilepsies: entering the 21st century. Epilepsia 2011 ; 52: 1058-1062

8. Panayiotopoulos CP. Clinical Aspects of the diagnosis of Epileptic Seizures and Epileptic Syndromes. In The Epilepsies 2005. Bladon Medical Publishers p1-5

9. Jones KL. Smith's Recognizable pattern of Human malformation $4^{\text {th }}$ ed. Philadelphia: Saunders 1988

10. WHO. Growth Reference data for Children from 5 to 19 years. 2007 www.who.int/ growthref/en/ ( accessed 22 May 2012)

11. Needlman RD. The First Year. In: Berhrman RE, Kielgman RM and Jenson HB (eds.) Nelson's Textbook of Pediatrics $17^{\text {th }}$ ed. Philadelphia: Saunders, 2004; pp31-38

12. Shann F, Biddulph J, and Vince J. Head circumference. In: Paediatrics for Doctors in Papua New Guinea. $2^{\text {nd }}$ ed. 2003 p.14.

13. Leonardi $\mathrm{M}$ and Ustum TB. The global burden of epilepsy. Epilepsia 2002 ; 43: 21S-25S

African Health Sciences Vol 13 Issue 3 September 2013 
14. Kasirye I. Determinants of Learning achievement in Uganda. Uganda: Economic Policy Research Unit. 2009 p1-40 www.csae.ox.ac.uk/conferences/2009-EdiA/papers/ 325-Kasirye.pdf (accessed 22May 2012)

15. Adewuya AO, Oseni SBA, Okeniyi JAO. School performance of Nigerian adolescents with epilepsy. Epilepsia 2006; 47:415-420

16. Ibekwe RC, Ojinnaka NC, Iloeje SO. Academic Performance of school children with epilepsy. West African Journal of Medicine 2008;27:74-77

17. UNICEF Education Statistical Tables no. 4 In State of the World's Children Oxford University Press, 1998 p10

18. Southern and Eastern Africa Consortium for Monitoring Educational Quality (SACME). Education in Uganda 1995-2012. Publ. SACME 2012

http://www.sacmeq.org/educationuganda.htm (accessed 22 May 2012)

19. Pazzaglia P, Pazzaglia L. Records in grade school of pupils with epilepsy. Epilepsia 1976; 17: 361 366

20. Elger C, Helmstaedter C. Chronic Epilepsy and cognition, The Lancet; Neurology 2004; 3 :663-72

21. Herman B, Seidenberg M. Epilepsy and cognition. Epilepsy Currents 2007; 7:1-6

22. Haut SR, Veliskova J. Susceptibility of immature and adult brains to seizure effects. The Lancet; Neurology 2004; 3 : 608-617

23. Thompson PJ, Duncan JS, Cognitive decline in severe intractable epilepsy. Epilepsia 2005; 46 :1780-1787

24. Banu SH, Jahan M, Koli UK, Ferdousi S, Khan NZ, Neville B. Side effects of phenobarbarbital and carbamazapine in childhood epilepsy: randomised controlled trial. British Medical Journal 2007; 334 : 1207-1210
25. Waruiru CM, Newton CRJC, Forster JC, New L, Winstanley P, Mwangi I, et al. Epileptic seizures and malaria in Kenyan children. Transactions of the Royal Society of Tropical Medicine 1996; 90:152-155

26. Holding PA, Stevenson J, Peshu N, Marsh K. Cognitive Sequelae of Severe Malaria with Impaired Consciousness. Transactions of the Royal Society of Tropical Medicine 1999; 93:529-534

27. WHO. Epilepsy management in the Africa region. In: Epilepsy in the WHO African region: Bridging the gap? 2004; 10-22 www.who.int/ mental_health/managment/epilepsyin_Africanregion ( accessed 22May 2012)

28. Baskind R ,Birbeck GL. Epilepsy-associated stigma in sub-Saharan Africa: the social landscape of a disease. Epilepsy and Behaviour 2005; 7: 6873

29. Coleman R, Loppy L, Walraven G. The treatment gap and primary health care for people with epilepsy in rural Gambia. Bulletin of the World Health Organisation 2002; 80: 378 383

30. Scott RA, Lhatoo SD, Sander JWA. The treatment of epilepsy in developing countries: where do we go from here? Bulletin WHO 2001;79: $344-351$

31. WHO 1995 Integrated management of childhood illness

www.who.int.child-adolescent-health/integr.htm (accessed May 22 2012)

32. Abdulla S, Schellenburg S, Nathan R, Mukasa O, Marchant T, Smith T, et al. Impact on malaria morbidity of a programme supplying insecticide treated bed-nets in children under 2 years. British Medical Journal 2001;322: 270-3 